Seção Temática: Balanço do Fundeb

Volume 11 - $2021 \mid$ n. 10

\title{
O Novo Fundeb É uma Vitória? Análise das disputas políticas pelo projeto do Novo Fundeb
}

Micaela Passerino Gluz

Universidade Federal do Rio Grande do Sul (UFRGS), Porto Alegre/RS - Brasil

\section{Resumo}

Este trabalho analisa a tramitação da Proposta de Emenda Constitucional (PEC) no 15/2015 da Câmara dos Deputados e $n^{\circ}$ 26/2020 do Senado Federal. Como objetivo específico, buscaremos analisar a dinâmica da disputa congressual da proposta do novo Fundo de Manutenção e Desenvolvimento da Educação Básica e de Valorização dos Profissionais da Educação (Fundeb), a partir de posicionamentos acerca da complementação da União. Foi utilizado o método da pesquisa documental de abordagem qualitativa. As fontes escolhidas são documentos produzidos pela Comissão Especial da PEC nº 15/2015 e da PEC n 26/2020 e por instituições sociais, em destaque a Campanha Nacional Pelo Direito à Educação e o Todos Pela Educação. Foi possível identificar que houve avanços, como a constitucionalização tanto do Fundeb como do Custo Aluno-Qualidade (CAQ), porém o projeto político do Novo Fundeb está longe de ser o ideal para a população brasileira.

Palavras-chave: Fundeb. Financiamento da Educação Básica. Complementação da União. Estado.

\section{Is The New Fundeb a Victory? An analysis of the political disputes over the New Fundeb's Project}

\section{Abstract}

This paper analyzes the procedure for the Constitutional Amendment Proposal (PEC) No. $15 / 2015$ of the Chamber of Deputies and No. 26/2020 of the Federal Senate. As a specific objective, we seek to analyze the dynamics of the congressional dispute over the proposal for the new Fund for the Maintenance and Development of Basic Education and the Valorization of Education Professionals (Fundeb), based on positions regarding the financial complementation of the Union. The method of documentary research with a qualitative approach was used. The sources chosen are documents produced by the Special Commission of PEC No. 15/2015 and PEC No. 26/2020 and by social institutions, in particular, Campanha Nacional pelo Direito à Educação and from Todos Pela Educação. It was possible to identify that there were advances, such as the constitutionalization of both Fundeb and the StudentQuality Cost (CAQ), however the political project of New Fundeb is far from being ideal for the Brazilian population.

Keywords: Fundeb. Basic education financing. Financial complementation of the Union. State. 


\section{Introdução}

Este trabalho tem como principal objetivo analisar a tramitação da Proposta de Emenda à Constituição (PEC) no 15/2015 da Câmara dos Deputados e $n^{\circ}$ 26/2020 do Senado Federal, chamada de PEC do novo Fundo de Manutenção e Desenvolvimento da Educação Básica e de Valorização dos Profissionais da Educação (Fundeb), que visa tornar o fundo um instrumento permanente de financiamento da educação básica pública, além de propor outras mudanças. Como objetivo específico, buscaremos analisar a dinâmica da disputa congressual da proposta do novo Fundeb a partir de posicionamentos acerca da complementação da União.

O Fundeb é uma política pública nacional baseada na subvinculação de recursos públicos para Manutenção e Desenvolvimento da Educação (MDE). No âmbito de cada estado e Distrito Federal (DF), existe um fundo com recursos municipais e estaduais, somados a uma complementação da União aos fundos de, no mínimo, $10 \%$ do valor total, que é distribuída apenas para os que não atingem o valor anual mínimo por aluno. A redistribuição do montante dos fundos, a partir da "cesta-Fundeb", é uma medida que ocorre de acordo com o número de matrículas da Educação Básica em cada rede, ou seja, os municípios e os estados contribuem com o Fundeb do seu estado, mas o retorno é dividido de acordo com a demanda de cada ente federado, no interior de cada estado.

O instrumento do Fundeb tornou-se um dos mecanismos mais importantes no trabalho de equalização do ensino obrigatório e na busca da universalização da educação no Brasil. Farenzena (2015) aponta que a política do Fundeb pode ser definida em linhas gerais pela vinculação e subvinculação de recursos públicos à educação básica, demarcando a importância do investimento da verba pública para políticas sociais, garantindo o direito social da educação; a (re)distribuição destes recursos de acordo com as competências de cada ente federado, que começou no Fundef, mas se aprimorou no Fundeb; a cooperação intergovernamental no financiamento da educação, em que há ações e intervenções de todos os níveis de governo (municipal, estadual e nacional).

A política de fundos se apresentou, ao longo dos anos, como um grande avanço para o combate das desigualdades financeiras entre os entes federados no tocante ao montante disponível para educação no Brasil, como analisa José Marcelino de Rezende Pinto (PINTO, 2019, p. 27):

Antes da implantação do Fundo de Manutenção e Desenvolvimento do Ensino Fundamental e de Valorização do Magistério (Fundef), em 1998, a diferença no gasto por aluno poderia atingir uma razão superior a dez entre as diferentes regiões do país e, mesmo, no interior de um mesmo estado, na comparação entre escolas mantidas pelo governo estadual e aquelas sob responsabilidade dos governos locais. Minimizar essa desigualdade foi um dos motivos da implantação da política de fundos, talvez o seu aspecto mais positivo.

O Fundeb como política pública encerrou sua vigência ao final de 2020, para substituir e aprimorar esse instrumento, tramita no Congresso Nacional a PEC do Novo Fundeb $\left(n^{\circ}\right.$ 15/2015 na Câmara dos Deputados e $n^{\circ}$ 26/2020 Senado Federal). Na tramitação surgiram emendas, defesas e sugestões de percentuais diversos para a complementação da União. A complementação da União provém de recursos públicos "novos" para a cesta-Fundeb, pois os outros recursos são verbas já vinculadas para a MDE e que são redistribuídos de acordo 
com as matrículas. Então, um aumento no percentual da complementação da União pode significar, se não constrangido por outros dispositivos, uma ampliação-de recursos públicos para a educação.

\section{Metodologia}

A metodologia utilizada neste estudo foi da técnica de pesquisa documental de abordagem qualitativa segundo Kripka, Scheller e Bonotto (2015, p. 4):

[...] a pesquisa documental é aquela em que os dados obtidos são estritamente provenientes de documentos, com o objetivo de extrair informações neles contidas, a fim de compreender um fenômeno; é um procedimento que se utiliza de métodos e técnicas para a apreensão, compreensão e análise de documentos dos mais variados tipos.

As fontes escolhidas são documentos como emendas, substitutivos, sugestões, etc., produzidos pela Comissão Especial da PEC n¹5/2015 da Câmara dos Deputados e PEC n ${ }^{\circ}$ 26/2020 do Senado Federal, assim como manifestações, notas técnicas, estudos e posicionamentos públicos produzidos por diversas instituições sociais, em destaque a Campanha Nacional Pelo Direito à Educação, que será referenciada pela sigla CNDE, e o Todos Pela Educação, que será referenciado pela sigla TPE.

\section{Campanha Nacional Pelo Direito à Educação e a Todos Pela Educação: disputa de projetos pelo "terceiro setor"}

Foram escolhidas a CNDE e o TPE por causa da relevância que essas entidades têm no campo político do qual fazem parte, sendo duas organizações que se dedicaram a produzir diversos materiais sobre o projeto político do Novo Fundeb e influenciaram diretamente as decisões e formulação das PECs.

A CNDE é uma rede cujo Comitê Diretivo é composto por diversas entidades da sociedade civil, como movimentos e sindicatos ${ }^{1}$. Segundo Ribeiro, Klemann e Ribeiro (2017, p. 158), a CNDE

[...] se constitui numa coalizão de organizações que atuam para garantir o direito à educação pública e de qualidade para todas as pessoas, por meio do exercício da política de accountability social. [...] a Campanha tem orientado comportamentos na esfera política que vêm transformando a relação Estado/sociedade e afetando a estrutura jurídico-normativa do País.

O TPE é uma Organização Não Governamental (ONG) que conta com apoio de diversas empresas e bancos como mantenedores e apoiadores da instituição, como a Fundação Bradesco, Itaú BBA e Itaú Social, Instituto Unibanco, Burger King entre outros. Segundo a análise de André Martins (2009, p. 26), o TPE:

1 Ação Educativa; ActionAid; Associação Nacional em Pesquisa de Financiamento da Educação (FINEDUCA); Centro de Cultura Luiz Freire (CCLF); Centro de Defesa da Criança e do Adolescente do Ceará (CEDECA-CE); Confederação Nacional dos Trabalhadores da Educação (CNTE); Movimento Interfóruns de Educação Infantil do Brasil (MIEIB); Movimento dos Trabalhadores Rurais Sem Terra (MST); União Nacional dos Conselhos Municipais de Educação (UNCME); União Nacional dos Dirigentes Municipais da Educação (UNDIME). 
[...] se materializa como organismo comprometido com as estratégias de hegemonia da classe empresarial no campo da educação, lutando para afirmar uma perspectiva restrita de formação humana para os trabalhadores brasileiros na atual configuração do capitalismo [...] Sua inserção na sociedade civil, embora definida como 'uma aliança' de esforços para o bem da nação, é, na verdade, uma forma inovadora de se obter consenso em torno de um projeto criado e dirigido pela classe empresarial. Nesse movimento, a responsabilidade social se afirma como referência ideológica que assegura a unidade política da 'direita para o social' em seu trabalho de legitimação da sociedade capitalista e de um projeto restrito de educação para as massas.

Ambas as entidades, com suas particularidades, compõem o "terceiro setor", instituições fora da dualidade do setor privado e do público, porém trabalham no sentido de uma reestruturação da função do Estado e do capital, como aponta Janaína Duarte (DUARTE, 2008, p. 61):

O termo terceiro setor está fundamentado na fragmentação da realidade em setores ('primeiro setor' o Estado, 'segundo setor' o mercado e 'terceiro setor' a sociedade civil), isolando e autonomizando cada um deles, não apresentando uma visão de totalidade social, como se os aspectos econômicos, políticos, sociais e culturais não tivessem uma íntima inter-relação e imbricamento no conjunto da sociedade. Essa compreensão identifica-se com uma visão liberal e funcionalista da sociedade que retira as reflexões econômicas do Estado e despolitiza o mercado e a sociedade civil; como se fosse possível fragmentar a realidade social. Tal fragmentação da realidade é necessária para o momento atual de reestruturação do capital e das suas premissas político-ideológicas, [...] perde-se a historicidade, a totalidade e a perspectiva de contradição para que o terceiro setor possa assumir funcionalidade no cenário de reestruturação do capital.

Após essa breve apresentação, a seguir trataremos sobre como ocorreu a disputa do projeto político do Novo Fundeb a partir de uma análise histórica das porcentagens dos valores da complementação da União, envolvendo os atores políticos citados acima.

\section{Complementação da União no Novo Fundeb}

O instrumento do Fundeb trabalha com subvinculação de recursos públicos já vinculados à MDE para a "cesta-Fundeb", $20 \%$ de impostos estaduais e municipais (BRASIL, 2007), ou seja, não há recurso novo para a educação no Fundeb dessa maneira. O que muda essa situação é a complementação da União, em que o ente federal complementa apenas os fundos que não atingem o valor mínimo por aluno anual.

Propor e defender um aumento na complementação da União é lutar por mais recursos públicos para a educação. No atual desenho quem investe mais no fundo são os municípios e estados e estes são os que menos têm disponibilidade financeira de arrecadação, como apontado anteriormente por José Marcelino Rezende Pinto (PINTO, 2007). Existe uma desigualdade entre os entes federados, de maneira que a União, que tem maior capacidade financeira, é o ente que menos contribui para o fundo. Tanto estados como municípios estão esgotados nesse sentido.

Feita essa introdução, foquemos em como esse tema foi tratado ao longo da tramitação do Novo Fundeb. No início da definição da PEC 15/15, o valor da complementação se manteve em $10 \%$. No primeiro substitutivo, da $55^{\circ}$ Legislatura da Câmara dos Deputados em 2017, a relatora Professora Dorinha (DEM/TO) aumentou esse valor para $30 \%$. 
Quadro 1 - Valores Complementação da União - $55^{\circ}$ Legislatura (1º Substitutivo) $^{2}$

\begin{tabular}{|c|c|c|c|}
\hline DATA & ORIGEM & DOCUMENTO & VALOR \\
\hline $09 / 11 / 2017$ & $\begin{array}{c}\text { Câmara dos Deputados - } \\
\text { Relatora Dorinha } \\
\text { (DEM/TO) }\end{array}$ & $\begin{array}{c}\text { Minuta de Substitutivo - } \\
55^{\mathrm{a}} \text { Legislatura }\end{array}$ & $30 \%$ \\
\hline $24 / 04 / 2018$ & $\begin{array}{c}\text { Campanha Nacional Pelo } \\
\text { Direito à Educação }\end{array}$ & $\begin{array}{c}\text { Nota Técnica - Análise e } \\
\text { Proposições de } \\
\text { Aprimoramento da Minuta } \\
\text { de Projeto Substitutivo à } \\
\text { PEC 15-A/2015 }\end{array}$ & $50 \%$ \\
\hline $06 / 2018$ & Todos Pela Educação & $\begin{array}{c}\text { Análise do Substitutivo à } \\
\text { Proposta de Emenda à } \\
\text { Constituição n' } 15 / 2015\end{array}$ & $15 \%-17 \%$ \\
\hline
\end{tabular}

Fonte: Elaboração da autora.

A partir do Quadro 1 é possível perceber a diferenciação que já se apresentava no início da tramitação da PEC, em que havia duas entidades, ambas com princípios de defesa da educação pública, que apresentavam propostas antagônicas de um projeto político para o Fundeb.

Com o fim da $55^{\circ}$ Legislatura na Câmara, é solicitada e atendida a demanda de reabertura dos trabalhos da PEC $15 / 15$ na $56^{\circ}$ Legislatura, e, em maio de 2019 , é apresentada a segunda minuta de substitutivo, em que a relatora, Professora Dorinha (DEM/TO), que se manteve de uma legislatura para outra, propôs em seu texto a manutenção de $30 \%$ da complementação da União. Esta apresentação foi aberta para o Plenário da Câmara, houve duas emendas e uma sugestão de emenda (enviada após o período oficial de envio de emendas), relativas à complementação da União, assim como manifestações da sociedade civil, conforme apresentadas no quadro abaixo:

Quadro 2 - Valores Complementação da União - $56^{\circ}$ Legislatura (2ºubstitutivo)

\begin{tabular}{|c|c|c|c|}
\hline DATA & ORIGEM & DOCUMENTO & VALOR \\
\hline $07 / 05 / 2019$ & Todos pela Educação & Fundeb Equidade & $15 \%$ \\
\hline $03 / 06 / 2019$ & $\begin{array}{c}\text { Deputada Tábata Amaral } \\
\left(\text { PDT/SP }^{3}\right) \text { e Felipe Rigoni } \\
\left(\text { PSB/ES }{ }^{4}\right)\end{array}$ & Emenda 3 & $15 \%$ \\
\hline $05 / 06 / 2019$ & $\begin{array}{c}\text { Sindicato dos Professores } \\
\text { e Servidores da Educação } \\
\text { do Ceará - SINDICATO } \\
\text { Deputados Waldenor } \\
\text { Pereira (PT/BA }{ }^{5} \text { e outros }- \\
\text { Emenda }\end{array}$ & Sugestões & $40 \%$ \\
\hline $06 / 06 / 2019$ & Emenda 5 & $40 \%$ \\
\hline
\end{tabular}

\footnotetext{
2 Todos os documentos analisados em todos os quadros estão disponibilizados nas referências.

3 Partido Democrático Trabalhista

4 Partido Socialista Brasileiro

5 Partido dos Trabalhadores
} 
O Novo Fundeb É uma Vitória?

\begin{tabular}{|c|c|c|c|}
\hline 07/06/2019 & $\begin{array}{c}\text { Presidentes e Vice- } \\
\text { Presidentes de Comissões } \\
\text { de Educação das }\end{array}$ & $\begin{array}{c}\text { Carta do } 1^{\circ} \text { Encontro } \\
\text { Nacional }\end{array}$ & $40 \%$ \\
\hline 10/06/2019 & $\begin{array}{l}\text { Ministério da Educação } \\
\text { (MEC) }\end{array}$ & $\begin{array}{c}\text { Ofício 1991/2019/MEC - } \\
\text { Sugestões do MEC ao } \\
\text { Parecer da Relatora }\end{array}$ & $15 \%$ \\
\hline $24 / 06 / 2019$ & $\begin{array}{l}\text { Campanha Nacional Pelo } \\
\text { Direito à Educação }\end{array}$ & $\begin{array}{c}\text { Novo Fundeb: } \\
\text { Em nome de um consenso } \\
\text { que promova o direito à }\end{array}$ & $40 \%$ \\
\hline 25/06/2019 & $\begin{array}{c}\text { Deputada Tábata Amaral } \\
\text { (PDT/SP) }\end{array}$ & Sugestão 6 & $10 \%$ \\
\hline 03/07/2019 & $\begin{array}{l}\text { Ministério da Educação } \\
\text { (MEC) }\end{array}$ & $\begin{array}{c}\text { Ofício 2382/2019/MEC - } \\
\text { Sugestões do MEC ao } \\
\text { Parecer da Relatora }\end{array}$ & $15 \%$ \\
\hline 08/2019 & Todos Pela Educação & $\begin{array}{l}\text { Nota Técnica: Análise da } \\
\text { relação entre investimento } \\
\text { por aluno e qualidade do }\end{array}$ & $15 \%$ \\
\hline 08/2019 & $\begin{array}{c}\text { União Nacional dos } \\
\text { Estudantes (UNE) e União } \\
\text { Brasileira de Secundaristas } \\
\text { (UBES) }\end{array}$ & Posicionamento Público & $40 \%$ \\
\hline 05/09/2019 & $\begin{array}{c}\text { União Nacional de } \\
\text { Dirigentes Municipais da } \\
\text { Educação (UNDIME) }\end{array}$ & $\begin{array}{l}\text { O novo Fundeb como } \\
\text { mecanismo de } \\
\text { financiamento }\end{array}$ & $40 \%$ \\
\hline 02/09/2019 & Todos Pela Educação & $\begin{array}{l}\text { Novo Fundeb: mais } \\
\text { redistributivo e mais } \\
\text { eficiente }\end{array}$ & $15 \%$ \\
\hline 18/09/2019 & $\begin{array}{c}\text { Câmara dos Deputados - } \\
\text { Relatora Dorinha } \\
\text { (DEM/TO) }\end{array}$ & $\begin{array}{c}2^{a} \text { Minuta do Substitutivo - } \\
56^{a} \text { Legislatura }\end{array}$ & $40 \%$ \\
\hline
\end{tabular}

Fonte: Elaboração da autora.

É possível perceber, no Quadro 2, que desde o início do ano de 2019 até setembro a complementação da União virou um "cabo de guerra", quando se apresentaram números de extremos diferentes, variando entre $40 \%$ e $10-15 \%$.

Referente ao documento FUNDEB Equidade, o TPE apresentou como proposta a necessidade de aumento na complementação da União, mas de forma "fiscalmente responsável, com previsão de origem dos recursos [...]" (TPE, 2019c, p. 68). No mesmo documento são apresentados cinco princípios para a discussão do Novo Fundeb, pelo ponto de vista do TPE, em que destacamos os dois primeiros (TPE, 2019c, p. 43):

1. É preciso aprimorar os mecanismos de financiamento da Educação Básica para que os recursos sejam melhor geridos, melhor distribuídos e também ampliados.

2. Não basta apenas elevar investimentos e distribuí-los melhor. É preciso haver mecanismos para indução de melhorias na eficiência e de avanços nos resultados.

Em audiência pública, no dia 22 de outubro de 2019, a presidenta do TPE, Priscila Cruz, reforçou as posições do TPE de maior atenção à forma de gestão e da alocação dos recursos, que o que mais importa não são mais recursos para a educação, mas sim uma melhor gestão educacional (BRASIL, 2019h): 
[...] não existe financiamento sem gestão e gestão sem financiamento, é verdade é muito desigual. O Brasil é muito desigual, é desigual em resultados, desigual em condições e a gente tem aqui uma situação [apontando para apresentação de ppt] que com investimentos diferentes resultados iguais e a mesma coisa, resultados iguais com investimentos diferentes, a gente precisa melhorar a alocação, a implementação, a melhoria constante dessas políticas, melhorias constantes na educação, o investimento importa mas o que mais explica é a gestão, é como você aplica esse dinheiro. [...] Vou falar da complementação da União, mas na lógica que a gente tem que ter maior eficiência nessa maior complementação da União se a gente simplesmente não olhar para modelagem se a gente só fizer a discussão de mais complementação da União o que a gente vai ter nesse novo fundeb, que, de novo, é uma oportunidade de dar um passo mais arrojado na direção de mais qualidade com equidade. Então, se a gente pegar aqui a PEC 65 de 2019 do senado, que só prevê uma maior complementação da União (40\%), o que a gente gera com isso aqui é que 12 bilhões de reais deixam de ir para os alunos, para os municípios que mais precisam, que estão numa situação de subfinanciamento que só aumenta, esse é o perigo das bandeiras vazias, hoje como a gente tá, que é os $10 \%$ aqui a gente já tá colocando no fundeb atual 4 bilhões e $700 \mathrm{mil}$ reais mas é que a gente deixa de colocar para os municípios e alunos que mais precisam [...] então não adianta a gente só aumentar a complementação da União se a gente não mexer nas regras internas desse Fundeb.

E, tanto na audiência pública como no documento, o TPE fez a defesa do percentual de $15 \%$ para a complementação da União, sob a justificativa de que o aumento de $5 \%$, no atual desenho da complementação, seria o suficiente para promover uma educação de qualidade, e que seria necessário fazer um debate real sobre o quanto é possível aumentar o percentual da complementação dentro do Orçamento da União (TPE, 2019c, p. 17).

Com os apontamentos feitos acima sobre a posição recorrente do TPE, desde sua primeira análise publicada em 2018 até análises e manifestações nas audiências públicas em outubro de 2019, é possível dizer que o TPE estimula um discurso ideológico de "ineficiência, desperdício" da atuação estatal, como apresentada nas análises de Janaína Duarte (DUARTE, 2008). O posicionamento do TPE reforça que a resposta para o financiamento da educação não é aumentar em larga escala a quantia de recursos, mas sim uma questão de gestão e eficiência. André Martins (2009) coloca que essa ação é um pensamento aliado ao do Banco Mundial dos anos 1990, que afirmava que não era necessário elevar os recursos para educação, que os recursos eram suficientes, mas o problema era de gestão, falta de eficiência.

O projeto político do TPE como projeto de nação, como descreve Erika Moreira Martins (2013), aponta para a ineficiência do Estado e de uma necessidade de corresponsabilidade na educação, em que os fundadores e mantenedores do TPE, o empresariado brasileiro, torna-se sujeito ativo na definição de políticas públicas (MARTINS, 2013, p. 66). Como analisa André Martins (2009, p. 26), a inserção do TPE, embora aparente ser um esforço em prol do bem da nação "[...] é, na verdade, uma forma inovadora de se obter consenso em torno de um projeto criado e dirigido pela classe empresarial".

Já em contraste com as propostas do TPE, os posicionamentos da CNDE analisados nos documentos do Quadro 1 e 2 apresentam percentuais maiores para complementação da União, de 50\% em abril de 2018 e 40\% em junho de 2019, e a maior argumentação da CNDE, para um grande percentual da complementação, é que os recursos destinados à educação, 
especificamente para o Fundeb, não são suficientes para oferecer uma educação de qualidade, segundo o direito de educação da Constituição (CAMPANHA..., 2020a, p. 50):

\begin{abstract}
Quando defendemos a complementação da União ao Fundeb, de no mínimo $40 \%$, estamos defendendo o direito à educação definido na Constituição, qual seja, como direito de todos, com oferta pública, gratuita, laica e de qualidade. A complementação da União de $40 \%$ ainda é insuficiente para promover justiça social entre as redes e garantir que todas as escolas públicas do país sejam dignas e preparadas para o desenvolvimento do processo de ensino-aprendizagem. [...] a simulação sobre o cumprimento do Custo Aluno-Qualidade Inicial (CAQi), realizada pelo SimCAQ indica que seria necessária uma complementação da União na ordem de $46,4 \%$ como condição para a realização de um padrão mínimo de qualidade em todo o país. Ou seja, essa é a conta na ponta do lápis.
\end{abstract}

A proposta da CNDE fez coro nos movimentos sociais e entidades como a União Brasileira dos Estudantes Secundaristas (UBES), União Nacional dos Estudantes (UNE) e União Nacional Dos Dirigentes Municipais Da Educação (UNDIME) se posicionam pela defesa de uma complementação de $40 \%$, compreendendo que os recursos gastos na educação não são o suficiente para promover uma educação de qualidade, muito menos que o problema da educação no Brasil reside apenas numa 'má gestão' ou ineficiência por parte dos gestores públicos.

Percebemos um antagonismo bem marcante, a disputa de dois extremos, entre $10 \%$ $15 \%$ a $50 \%$, no Novo Fundeb, que define projetos diferentes para a educação básica brasileira. Um projeto que se baseia na eficiência dos gastos no financiamento da educação, cuja prioridade para a educação básica não deve ser mais verba, mas saber gerir esses gastos, e um projeto que aponta a necessidade de aumentar os gastos em educação básica a fim de aumentar a qualidade da educação pública brasileira.

Ambas as posições reverberaram na Câmara dos Deputados. A deputada Tábata Amaral (PDT/SP) e o deputado Felipe Rigoni (PSB/ES) escreveram a Emenda $n^{\circ} 3$, que solicitava uma complementação com percentual em $15 \%$, justificando-se com os documentos e defesas do TPE; enquanto a relatora Dorinha (DEM/TO) escreveu um $2^{\circ}$ Substitutivo, em junho, que aumentava o percentual de complementação para $40 \%$, supõe-se que concordando com as argumentações da CNDE, movimentos sociais e entidades como UNE, UBES e UNDIME.

É importante destacar a tramitação simultânea da PEC 65/2019, no Senado, iniciada em maio de 2019, com texto construído pela CNDE com governadores, Undime e Consed (CNDE, junho 2019), que indicava como mínimo para complementação o percentual de $40 \%$. Nesse contexto, é possível colocar que a movimentação da outra casa legislativa com uma PEC de mesma matéria e propostas diferentes gerou pressão para que a deputada Dorinha (DEM/TO) fizesse modificações na PEC 15/2015, com o aumento de recursos.

A decisão da deputada Dorinha (DEM/TO) em propor aumento do percentual da complementação no $2^{\circ}$ Substitutivo provocou diferentes reações nos sujeitos políticos envolvidos na construção do Novo Fundeb.

Nesse sentido, o presidente da Câmara, Rodrigo Maia (DEM/RJ), em outubro de 2019, apresentou críticas publicamente e se opôs ao valor de $40 \%$ para a complementação da União, colocando que "o debate do Fundeb trava se não for para o mundo real" (PINHO, 2019). Anteriormente a isso, o Ministério de Educação (MEC) do governo Bolsonaro-Mourão 
enviou para a deputada Dorinha (DEM/TO) dois ofícios com sugestões, indicando percentuais de até $15 \%$ para a complementação, com a mesma justificativa para ambos os ofícios, sem apresentar argumentos para a solicitação (BRASIL, 2019f, p. 7; BRASIL, 2019g, p. 3):

\section{Justificativa: Propõe-se que a Complementação da União seja elevada ao patamar mínimo de $15 \%$, numa escala progressiva de $1 \%$ ao ano, partindo do percentual mínimo de $10 \%$ no primeiro ano de vigência do novo Fundo.}

Existindo pressão da presidência da Câmara dos Deputados e do governo federal, a relatora Professora Dorinha (DEM-TO) apresentou à Comissão Especial, em fevereiro de 2020, um relatório com proposta de minuta de substitutivo em que a complementação da União diminui para $20 \%$, além de serem alterados outros pontos do relatório de setembro.

No início de março de 2020, a pandemia do COVID-19 e os processos de quarentena estouraram no Brasil, a atenção dos gestores e políticos se voltaram principalmente para a pandemia e suas consequências, causando uma interrupção nos debates do Novo Fundeb, o que acarretou numa modificação da forma tradicional de organizar pressões políticas. As entidades e movimentos sociais realizaram um trabalho de manifestação e propaganda muito mais no formato remoto, abaixo segue o Quadro $3 \mathrm{com}$ as movimentações da Câmara dos Deputados no ano de 2020:

Quadro 3 - Valores Complementação da União - $56^{\circ}$ Legislatura $\left(3^{\circ} \mathrm{E} 4^{\circ}\right.$ Substitutivo)

\begin{tabular}{|c|c|c|c|}
\hline DATA & ORIGEM & DOCUMENTO & VALOR \\
\hline $27 / 01 / 2020$ & $\begin{array}{c}\text { Campanha Nacional Pelo } \\
\text { Direito à Educação }\end{array}$ & $\begin{array}{c}\text { CARTA Á SOCIEDADE BRASILEIRA } \\
\text { DUPLICAR A COMPLEMENTAÇÃO DA UNIÃO } \\
\text { AO FUNDEB É UMA VITÓRIA }\end{array}$ & $20 \%$ \\
\hline $8 / 02 / 2020$ & $\begin{array}{l}\text { Câmara dos Deputados } \\
\text { - Professora Dorinha } \\
\text { (DEM/TO) }\end{array}$ & $3^{\circ}$ Substitutivo & $20 \%$ \\
\hline $18 / 02 / 2020$ & Todos Pela Educação & Posicionamento Público & $20 \%$ \\
\hline $20 / 02 / 2020$ & $\begin{array}{c}\text { Campanha Nacional } \\
\text { Pelo Direito à Educação }\end{array}$ & $\begin{array}{c}\text { Posicionamento Público: O Brasil está distante } \\
\text { de um novo Fundeb capaz de consagrar o } \\
\text { direito à educação }\end{array}$ & $\begin{array}{l}\text { Não defende novo valor } \\
\text { para complementação }\end{array}$ \\
\hline $28 / 02 / 2020$ & FINEDUCA & $\begin{array}{l}\text { Por um Fundeb mais justo e com maior } \\
\text { compromisso da União! }\end{array}$ & $40 \%$ \\
\hline 03/03/2020 & $\begin{array}{l}\text { Campanha Nacional } \\
\text { Pelo Direito à Educação }\end{array}$ & $\begin{array}{c}\text { Nota Técnica: Sugestões para o } \\
\text { estabelecimento de um Fundeb capaz de } \\
\text { colaborar com a consagração do direito à } \\
\text { educação }\end{array}$ & $40 \%$ \\
\hline 04/03/2020 & $\begin{array}{l}\text { Deputada Sâmia } \\
\text { Bomfim (PSOL/SP) e } \\
\text { Edmilson Rodrigues } \\
\quad\left(\text { PSOL/PA }{ }^{6}\right)\end{array}$ & Voto em separado & $40 \%$ \\
\hline
\end{tabular}

\footnotetext{
6 Partido Socialismo e Liberdade
} 


\begin{tabular}{|c|c|c|c|}
\hline $13 / 04 / 2020$ & FINEDUCA & $\begin{array}{l}\text { Em defesa de novos recursos para } \\
\text { complementação da União ao Fundeb }\end{array}$ & $\begin{array}{l}\text { Não defende novo valor } \\
\text { para complementação }\end{array}$ \\
\hline $12 / 05 / 2020$ & $\begin{array}{l}\text { Campanha Nacional } \\
\text { Pelo Direito à Educação }\end{array}$ & $\begin{array}{l}\text { Posicionamento Público: O Fundeb em novo } \\
\text { cenário: a pandemia da COVID-19 }\end{array}$ & $\begin{array}{l}\text { Não defende novo valor } \\
\text { para complementação }\end{array}$ \\
\hline 02/06/2020 & Todos Pela Educação & $\begin{array}{c}\text { Ofício à Comissão Especial da Câmara dos } \\
\text { Deputados que analisa a PEC } n^{\circ} 015 / 2015, \\
\text { que torna permanente o Fundeb }\end{array}$ & $\begin{array}{l}\text { Não defende novo valor } \\
\text { para complementação }\end{array}$ \\
\hline $15 / 06 / 2020$ & $\begin{array}{l}\text { Campanha Nacional } \\
\text { Pelo Direito à Educação }\end{array}$ & $\begin{array}{l}\text { Carta Aberta às Parlamentares e aos } \\
\text { Parlamentares é preciso votar um "Fundeb pra } \\
\text { Valer!", preservando a alimentação escolar e } \\
\text { demais programas educacionais }\end{array}$ & $\begin{array}{l}\text { Não defende novo valor } \\
\text { para complementação }\end{array}$ \\
\hline $10 / 07 / 2020$ & $\begin{array}{l}\text { Câmara dos Deputados } \\
\text { - Professora Dorinha } \\
\text { (DEM/TO) }\end{array}$ & $4^{\text {a }}$ Minuta do Substitutivo & $20 \%$ \\
\hline 18/07/2020 & $\begin{array}{l}\text { Ministro da Economia - } \\
\text { Governo Federal }\end{array}$ & Contraproposta & $\begin{array}{l}10 \% \text { para o Fundeb e } \\
10 \% \text { para o Renda } \\
\text { Brasil }\end{array}$ \\
\hline $21 / 07 / 2020$ & UNE e UBES & Posicionamento Público & $\begin{array}{l}\text { Não defende novo valor } \\
\text { para complementação }\end{array}$ \\
\hline $21 / 07 / 2020$ & $\begin{array}{c}\text { Câmara dos Deputados } \\
\text { - Professora Dorinha } \\
\text { (DEM/TO) }\end{array}$ & Texto aprovado PEC 15/15 & $23 \%$ \\
\hline
\end{tabular}

Fonte: Elaboração dos autores.

Antes de a deputada Dorinha (DEM/TO) apresentar à Comissão Especial a $3^{a}$ proposta de Substitutivo, a CNDE publicou em seu site oficial uma carta colocando a concordância do movimento no percentual de $20 \%$ para a complementação, com a justificativa de que havia outras questões que necessitavam de mais atenção e trabalho naquele momento. Importante colocar que a vigência do Fundeb 1 era até 31/12/2020, o que preocupava não apenas parlamentares, mas também a própria CNDE, trabalhadores da educação, estudantes e movimentos sociais, logo, a aprovação de um Novo Fundeb tinha data limite, o final do ano de 2020. Segue abaixo um trecho da carta produzida pela CNDE justificando sua mudança de tática (CNDE, 2020a):

Diante de nossa História, é necessário explicar que a Campanha Nacional pelo Direito à Educação defende um valor de complementação da União ao Fundeb pautado pelos mecanismos de Custo Aluno-Qualidade Inicial (CAQi) e Custo Aluno-Qualidade (CAQ), instrumentos criados e desenvolvidos pela própria Campanha desde 2002, com a inestimável contribuição do Prof. José Marcelino de Rezende Pinto (USP). Com base nesse critério, a complementação da União teria que ser de, no mínimo, 50\%. Contudo, no curso dos debates parlamentares, convencionou-se um patamar de, no mínimo, $40 \%$. No entanto, diante da desfavorável correlação de forças no Congresso Nacional e frente ao governo de Jair Messias Bolsonaro, acertou-se o patamar de 20\%. Considerando esse cenário, duplicar a complementação da União ao Fundeb é uma incontestável conquista - que precisa ser confirmada. 
As principais problemáticas trazidas no $3^{\circ}$ Substitutivo, além de um percentual para a complementação menor, foram de deixar em aberto o uso dos recursos do salário-educação, podendo ser incorporado à complementação da União e prejudicando programas nacionais que dependem desses recursos financeiros para serem mantidos, assim como a retirada do CAQ no texto e tentativas de privatização dos recursos públicos da educação básica (CAMPANHA..., 2020a).

Destacamos como principal ator contra um maior percentual da complementação da União o governo federal, nas figuras do Presidente Jair Messias Bolsonaro, dos Ministros da Educação Abraham Weintraub (até 19 de junho de 2020) e Milton Ribeiro (atual) e do Ministro de Economia Paulo Guedes, primeiramente por se ausentar dos espaços de construção política do Novo Fundeb, participando de pouquíssimas audiências públicas e reuniões convocadas, segundamente por enviarem ofícios de exigências, mesmo não participando de espaços para diálogos, com o intuito, em nossa análise, de minar qualquer tentativa divergente do projeto político do governo federal para educação e a economia do País.

Dois dias antes da votação na Câmara dos Deputados, o governo federal, através da ação do Paulo Guedes, ministro da Economia, apresentou uma contraproposta ao Novo Fundeb para parlamentares de centro-direita, que foram buscados para apoiarem o governo Bolsonaro. A contraproposta modificava substancialmente o projeto da PEC, de modo que, além de querer adiar a votação da PEC do Novo Fundeb para 2022, propunha manter os atuais $10 \%$ de complementação da União para o Fundeb, assim como já existente na Emenda Constitucional (EC) que criou o Fundeb 1, e os outros 10\%, sobre os quais já havia consenso entre os parlamentares que seriam acrescidos à contribuição, seriam destinados ao financiamento do Renda Brasil, programa em elaboração pelo Ministro da Economia, supostamente para substituir o Bolsa Família. Assim, mais do que uma proposta para o Fundeb, tratava-se de uma tentativa do governo Bolsonaro de pressionar o Congresso Nacional para aprovar projetos de sua autoria, abocanhando recursos já consensualizados para outras finalidades.

Apesar da pressão do governo Bolsonaro em diminuir a complementação da União e, de última hora, modificar o caráter desse repasse da União, os(as) parlamentares não atenderam às exigências do presidente Bolsonaro e do Ministro da Economia Paulo Guedes. Isso demonstrou as divergências políticas entre governo federal e Câmara dos Deputados. Nesse sentido, pode ser útil a análise de Alysson Mascaro sobre a dinâmica de relações políticas envolvendo instituições estatais e sociais (MASCARO, 2013, p. 35-36):

\section{[...] é preciso entender a dinâmica das instituições estatais enredadas num amplo quadro de relações com múltiplas instituições sociais. Entre instituições estatais e instituições sociais há vínculos necessários e variados, tão distintos quanto as próprias dinâmicas sociais e tão conflituosos quanto as próprias lutas de classes e a pluralidade dos grupos sociais. [...] há relações que vão tanto de um eventual desconhecimento mútuo até a total implicação estrutural ou funcional.}

Apesar desses processos de disputas contraditórios, e tentativas de última hora de modificações, o texto final, apresentado em 10 de julho de 2020, foi enviado sem alterações para a votação na Câmara dos Deputados. Após muita disputa congressual, principalmente por parte dos deputados do partido NOVO durante a discussão no Plenário, que requer uma 
análise mais minuciosa em um outro trabalho, o texto foi enviado para o Senado Federal com o valor de complementação de $23 \%$.

Quadro 4 - Valores de Complementação da União (Senado Federal)

\begin{tabular}{|c|c|c|c|}
\hline DATA & ORIGEM & DOCUMENTO & VALOR \\
\hline 29/07/2020 & $\begin{array}{c}\text { Senado Federal - Relatório } \\
\text { Flávio Arns }\end{array}$ & $1^{\circ}$ Relatório Legislativo & $23 \%$ \\
\hline 05/08/2020 & $\begin{array}{c}\text { Campanha Nacional Pelo Direito } \\
\text { à Educação }\end{array}$ & $\begin{array}{c}\text { A PEC do Fundeb e o CAQ como } \\
\text { instrumento de controle da } \\
\text { aplicação dos recursos } \\
\text { educacionais } \\
\end{array}$ & $\begin{array}{l}\text { Não defende novo } \\
\text { valor para } \\
\text { complementação }\end{array}$ \\
\hline $17 / 08 / 2020$ & $\begin{array}{l}\text { Senador Jorge Kajuru } \\
\text { (CIDADANIA/GO) }\end{array}$ & Emenda 5 & $30 \%$ \\
\hline $17 / 08 / 2020$ & $\begin{array}{c}\text { Campanha Nacional Pelo Direito } \\
\text { à Educação }\end{array}$ & $\begin{array}{c}\text { Posicionamento Público: Senado } \\
\text { Federal a educação pública exige } \\
\text { um Fundeb com CAQ }\end{array}$ & $\begin{array}{l}\text { Não defende novo } \\
\text { valor para } \\
\text { complementação }\end{array}$ \\
\hline $20 / 08 / 2020$ & $\begin{array}{c}\text { Senado Federal - Relatório } \\
\text { Flávio Arns }\end{array}$ & $2^{\circ}$ Relatório Legislativo & $23 \%$ \\
\hline $26 / 08 / 2020$ & $\begin{array}{l}\text { Câmara dos Deputados e } \\
\text { Senado Federal }\end{array}$ & Emenda Constitucional 108/2020 & $23 \%$ \\
\hline
\end{tabular}

Fonte: Elaboração dos autores.

No Quadro 4, percebe-se que, o grande momento de disputa do projeto político do Novo Fundeb, deu-se na Câmara dos Deputados. Nesse sentido, vemos que não houve disputa no Senado, supõe-se que pela preocupação e receio de não aprovar uma proposta para o Novo Fundeb em tempo para implementação a partir do ano de 2021. Apesar de terem sido elaboradas emendas à PEC $n^{\circ} 26 / 2020$, algumas foram retiradas pelos próprios senadores que as propuseram, e algumas não tiveram assinaturas suficientes para serem levadas em conta no relatório final.

A partir dos dados levantados, é possível realizar algumas conclusões sobre a tramitação do Novo Fundeb, a complementação da União e ações políticas do TPE e da CNDE.

Sobre o TPE, primeiramente destacamos a precariedade dos materiais do site oficial da organização, a consolidação dos arquivos era confusa, não datavam todos os materiais (posicionamentos, análises, notícias, manifestações, etc.), além de desativarem links com esses materiais ${ }^{7}$. Acreditamos que essa ação não deva ser considerada apenas como um mero deslize ou algum problema técnico, refletimos que essa movimentação se dê com o intuito e interesse de um apagamento histórico sobre os posicionamentos da organização.

Além disso, elencamos que o TPE atuou dentro da disputa do Novo Fundeb com um discurso ideológico de combate à ineficiência e ineficácia, muito mais do que com a

7 Como exemplo apresentamos este link, que não está mais ativo: https://todospelaeducacao.org.br/conteudo/TodosPela-Educacao-apresenta-proposta-para-Novo-Fundeb-ao-CNE. Acesso em: 02 jun. 2020. 
necessidade de aumento de recursos, pensamento alinhado com o empresariado brasileiro, como aponta André Martins (2009, p. 26):

\begin{abstract}
Sua penetração nas instâncias do Executivo e do Legislativo, e a transformação de sua proposição em lei, embora definida sob o argumento da 'parceria', é, de fato, uma tática empregada nas relações de hegemonia. O que significa dizer que empresários organizados no TPE demonstram compreender que a configuração da sociedade brasileira na atualidade exige ações mais articuladas e requintadas quando comparadas com as ações no passado.
\end{abstract}

Essa compreensão nos leva a apontar uma relação intrínseca da atuação do TPE com a defesa de projeto capitalista da educação e representando os interesses do empresariado que o financia, fazendo jus à análise de Duarte (2008, p. 60), que coloca a função do "terceiro setor" como um

[...] fenômeno fluído e funcional ao processo de reestruturação do capital, inserido na perspectiva de totalidade e nas contradições da sociedade capitalista contemporânea, representando interesses da classe dominante e, assim, caracterizando-se como estratégia de consenso e hegemonia.

Sobre a atuação da CNDE, primeiramente destacamos que, ao contrário do TPE, todos seus links antigos permanecem ativos até a conclusão deste artigo; também datavam corretamente todas suas postagens, sejam notícias, análises, documentos, manifestações, posicionamentos, apresentações em audiências públicas, etc. Este trabalho da entidade contribui positivamente para as análises.

A mudança de tática da organização foi coerente ao concordar com um percentual menor do que defendiam no início da tramitação por conta de outras problemáticas que colocavam em risco a construção do Novo Fundeb. Em um contexto político com um governo federal abertamente conservador e liberal, pode-se considerar o Novo Fundeb uma vitória parcial, contendo avanços como o aumento do percentual da complementação da União, porém não o esperado no início da tramitação e muito menos o necessário para promover uma educação de qualidade.

Por fim, a disputa da PEC do Novo Fundeb se encerra no final de agosto com a promulgação da EC 108/2020, e, futuramente, abre-se um novo caminho de disputa política que será o projeto e regulamentação da lei.

\title{
Considerações Finais
}

Pelo exposto, é possível afirmar que houve uma intensa disputa em torno do projeto político do Novo Fundeb, principalmente sobre a complementação da União. As duas organizações analisadas, o TPE e a CNDE, estiveram envolvidas ativamente nos processos de discussão e decisão na tramitação da PEC 15/2015, porém com visões diferentes.

O TPE justificou, do início da tramitação até o fim, que não havia necessidade de aumentar a contribuição da União ao fundo para além de $15 \%$, que apenas o aumento do percentual de $15 \%$ era o suficiente para promover uma educação de qualidade e que um dos principais problemas do financiamento da educação era a ineficiência e ineficácia em gerir os recursos. Vale ressaltar que esse mesmo valor de percentual era defendido pelo governo federal, que fez tentativas de comprometer o projeto do Novo Fundeb ao pressionar o Congresso Nacional em incluir propostas de outros projetos de sua autoria. 
O projeto político da CNDE para o Novo Fundeb alinhava-se às posições dos movimentos sociais, como visto nos Quadros 2 e 3. Especificamente sobre a complementação da União, a CNDE, desde o início da tramitação, colocou a necessidade de um aumento considerável, um percentual mínimo de $40 \%$. Através de seus estudos, a CNDE apontou a falta de recursos financeiros para garantir uma educação de qualidade, principalmente quanto à valorização dos profissionais da educação. Infelizmente, por conta da pressão política do governo federal e do Presidente da Câmara na época, Rodrigo Maia, houve retrocessos em outras questões do projeto do Novo Fundeb, o que fez com que a CNDE recuasse e acordasse, com a deputada Dorinha (DEM/TO), um percentual de $20 \%$, para que pudessem focar em modificar os outros retrocessos.

Nesse sentido, respondendo à pergunta do título, O Novo Fundeb é uma vitória?, podese afirmar que se trata de uma vitória parcial. Houve avanços, como a constitucionalização do Fundeb, o aumento do percentual da complementação da União, porém, o projeto político do Novo Fundeb está longe de ser o ideal e o necessário para a população brasileira. Para essa compreensão, elencamos principalmente os estudos da CNDE, que apontam a necessidade de aumento de recursos a fim de promover-se uma educação verdadeiramente de qualidade no País.

\section{Referências}

BRASIL. Lei $n^{\circ}$ 11.494, de 20 de junho de 2007 (Lei do Fundeb). Diário Oficial da União, Brasília, DF, 2007.

BRASIL. Câmara dos Deputados. Minuta de Substitutivo à Proposta de Emenda à Constituição de no 15 de 2015 - 55 Legislatura. Apresentado em 2017. Brasília, 2017.

BRASIL. Câmara dos Deputados. Minuta de Substitutivo à Proposta de Emenda à Constituição de $n^{\circ} 15$ de 2015 - 56 ${ }^{\text {a }}$ Legislatura. Apresentada em maio de 2019. Brasília, 2019a.

BRASIL. Câmara dos Deputados. Emenda $n^{\circ}$ 2, de 03 de junho de 2019 à Comissão Especial da PEC 15/2015. Apresentada em junho de 2019. Brasília, $2019 \mathrm{~b}$.

BRASIL. Câmara dos Deputados. Emenda n 5, de 06 de junho de 2019 à Comissão Especial da PEC 15/2015. Apresentada em junho de 2019. Brasília, 2019c.

BRASIL. Câmara dos Deputados. Sugestão à PEC 15 de 2015 - Sugestão nº $^{\circ} 06$. Apresentada em 25 de junho de 2019. Brasília, 2019d.

BRASIL. Câmara dos Deputados. $2^{\mathrm{a}}$ Minuta de Substitutivo à Proposta de Emenda à Constituição de no 15 de 2015 - 56 ${ }^{\text {a }}$ Legislatura. Apresentada em setembro de 2019. Brasília, 2019e.

BRASIL. Câmara dos Deputados. Ofício 1991/2019/MEC - Sugestões do MEC ao Parecer da Relatora. Apresentada em 10 de junho de 2019. Brasília, 2019f.

BRASIL. Câmara dos Deputados. Ofício 2382/2019/MEC - Novas sugestões à PEC n $^{\circ}$ 15/2015 - FUNDEB. Apresentada em 03 de julho de 2019. Brasília, 2019g.

BRASIL. Câmara dos Deputados. PEC 015/15 - TORNA PERMANENTE O FUNDEB I EDUCAÇÃO - Audiência Pública Ordinária. TEMA: 'Discussão e Votação de Proposta'. 
O Novo Fundeb É uma Vitória?

Realizada no dia 22 de outubro de 2019. Brasília, 2019h. Disponível em: https://www.camara.leg.br/evento-legislativo/58086. Acesso em: 06 mar 2021.

BRASIL. Câmara dos Deputados. Propostas ao FUNDEB - Sugestão no 12. Apresentada em 05 de fevereiro de 2020. Brasília, 2020a.

BRASIL. Câmara dos Deputados. Relatório com Minuta de Substitutivo à Proposta de Emenda à Constituição de $n^{\circ} 15$ de 2015 - 56 ${ }^{\text {a }}$ Legislatura. Apresentada em 18 de fevereiro de 2020. Brasília, 2020b.

BRASIL. Câmara dos Deputados. Voto Em Separado (Dos Srs. Sâmia Bomfim e Edmilson Rodrigues). Apresentada em 04 de março de 2020. Brasília, 2020c.

BRASIL. Câmara dos Deputados. $3^{a}$ Minuta de Substitutivo à Proposta de Emenda à Constituição de $\mathbf{n}^{\circ} 15$ de 2015 - 56 ${ }^{\text {a }}$ Legislatura. Apresentada em 10 de julho de 2020. Brasília, 2020d.

BRASIL. Câmara dos Deputados. Redação Final à Proposta de Emenda à Constituição de

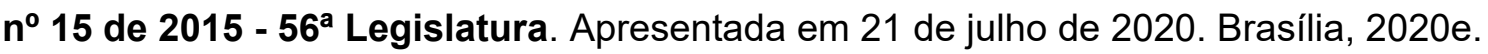

BRASIL. Senado Federal. $1^{\circ}$ Relatório Legislativo. Apresentada em 29 de julho de 2020. Brasília, 2020f.

BRASIL. Senado Federal. Emenda $n^{\circ}$ 06, de 17 de agosto de 2020 à Proposta de Emenda à Constituição no 26/2020. Apresentada em 17 de agosto de 2020. Brasília, 2020g.

BRASIL. Senado Federal. $\mathbf{2}^{\circ}$ Relatório Legislativo. Apresentada em 20 de agosto de 2020. Brasília, 2020h.

BRASIL. Senado Federal e Câmara dos Deputados. Constituição (2020). Emenda Constitucional № 108, de 26 de Agosto de 2020. Brasília, 2020i.

CAMPANHA Nacional Pelo Direito À Educação. Nota Técnica "Novo Fundeb: em nome de um consenso que promova o direito à educação". 2019a. Disponível em: https://www2.camara.leg.br/atividade-legislativa/comissoes/comissoes-

temporarias/especiais/56a-legislatura/pec-015-15-fundeb/documentos/sugestoes/NotaT ecnicaPorUmConsensoNoFundebCampanha.pdf. Acesso em: 15 set. 2020.

CAMPANHA Nacional Pelo Direito À Educação. Fundeb: o Brasil precisa de um fundo capaz de consagrar o direito à educação básica pública, gratuita e de qualidade. (Posicionamento Público). Setembro de 2019b. Disponível em: https://media.campanha.org.br/acervo/ documentos/NovoFundeb_CamaradosDeputados_2019_09_24_MinutaSubstitutivo_Dorinha _PEC15-2015-PosicionamentoCampanha.pdf. Acesso em: 15 set. 2020.

CAMPANHA Nacional Pelo Direito À Educação. Carta à Sociedade Brasileira: duplicar a complementação da união ao fundeb é uma vitória. 2020a. disponível em: https://campanha.org.br/noticias/2020/01/27/campanha-participa-de-acordo-sobre-o-

percentual-de-complementacao-da-uniao-ao-fundeb-no-minimo-20/. Acesso em: 06 mar. 2021.

CAMPANHA Nacional Pelo Direito À Educação. O Brasil está distante de um novo Fundeb capaz de consagrar o direito à educação. (Posicionamento Público). Fevereiro de 2020b. 
Disponível em: https://campanha.org.br/noticias/2020/02/20/o-brasil-esta-distante-de-umnovo-fundeb-capaz-de-consagrar-o-direito-educacao/. Acesso em: 15 set. 2020.

CAMPANHA Nacional Pelo Direito À Educação. O Fundeb em novo cenário: a pandemia da COVID-19. (Posicionamento Público). Maio de 2020c. Disponível em:https://media.campanha .org.br/acervo/documentos/Posicionamento_P\%C3\%BAblico_-

_Fundeb_no_contexto_de_pandemia.pdf. Acesso em: 15 set. 2020.

CAMPANHA Nacional Pelo Direito À Educação. Carta Aberta às Parlamentares e aos Parlamentares: é preciso votar um "fundeb pra valer!", preservando a alimentação escolar e demais programas educacionais. Junho de 2020d. Disponível em: https://media.c ampanha.org.br/acervo/documentos/NovoFundeb_CamaradosDeputados_2020_06_15_Rel atorioComissaoEspecial_Dorinha_PEC15-2015-CartaAbertaCampanha.pdf. Acesso em: 15 set. 2020.

CAMPANHA Nacional Pelo Direito À Educação. A PEC do Fundeb e o CAQ como instrumento de controle da aplicação dos recursos educacionais. (Posicionamento Público). Agosto de 2020e. Disponível em:https://media.campanha.org.br/acervo/ documentos/NovoFundeb_SenadoFederal_2020_08_05_Relatorio-FlavioArns_PEC26-2020PosicionamentoEntidadesEduc-OrgaosControle-CAQ.pdf. Acesso em: 15 set. 2020.

CAMPANHA Nacional Pelo Direito À Educação. Senado Federal: a educação pública exige um Fundeb com CAQ. (Posicionamento Público). Agosto de 2020f. Disponível em: https://media.campanha.org.br/acervo/documentos/NovoFundeb_SenadoFederal_2020_08_ 17_Relatorio-FlavioArns_PEC26-2020-PosicionamentoPublicoCampanha.pdf. Acesso em: 15 set. 2020.

DUARTE, Janaína Lopes do Nascimento. Funcionalidade do Terceiro Setor e das ONGS no Capitalismo Contemporâneo: O Debate Sobre Sociedade Civil E Função Social. Libertas, Juiz de Fora, v. 8, n. 1, p. 50-72, jan./jun. 2008.

FARENZENA, Nalú. Capacidades de Financiamento da Educação Básica no Fundeb: uma costura. In: GOUVEIA, Andrea Barbosa; PINTO, José Marcelino de Rezende; FERNANDES, Maria Dilnéia Espíndola (Org.). Financiamento da Educação no Brasil: os desafios de gastar 10\% do PIB em dez anos. Campo Grande: Editora Oeste, 2015. p. 83-107.

FINEDUCA. Associação Nacional de Pesquisa em Financiamento da Educação. Posicionamento Público: Em defesa de novos recursos para complementação da União ao Fundeb. Abril de 2020. Disponível em: https://fineduca.org.br/wp-content/uploads/2020/04/2 0200409_Fineduca_Nota_MDE-e-Compl-Unia\% CC\%83o-Fundeb.pdf. Acesso em: 15 set. 2020.

KRIPKA, Rosana Maria Luvezute; SCHELLER, Morgana; BONOTTO, Danusa de Lara. Pesquisa documental na pesquisa qualitativa: conceitos e caracterização. Revista de Investigaciones Unad, Bogotá, Colômbia, v. 14, n. 2, p. 55-73, dez. 2015.

MARTINS, André Silva. A Educação Básica No Século XXI: o projeto do organismo "Todos pela Educação. Práxis Educativa, Ponta Grossa, v. 4, n. 1, p. 21-28, jun. 2009. 
MARTINS, Erika Moreira. Movimento Todos Pela Educação: um projeto de nação para a educação brasileira. 2013. 184 f. Dissertação (Mestrado) - Curso de Mestrado em Educação, Universidade Estadual de Campinas, Campinas, 2013.

MASCARO, Alysson Leandro. Estado e Forma Política. São Paulo: Boitempo Editorial, 2013.

PINHO, Angela. Maia diz que debate do Fundeb trava se não for para o mundo real. Folha de São Paulo, São Paulo, 28 out. 2019. Disponível em: https://www1.folha.uol.com .br/educacao/2019/10/maia-diz-que-debate-do-fundeb-trava-se-nao-for-para-o-mundoreal.shtml. Acesso em: 10 set. 2020.

PINTO, José Marcelino de Rezende. A política recente de fundos para o financiamento da educação e seus efeitos no pacto federativo. Educação e Sociedade, Campinas, v. 28, n. 100, p. 877-898, out. 2007.

PINTO, José Marcelino de Rezende. A política de fundos no Brasil para o financiamento da educação e os desafios da equidade e qualidade. Propuesta Educativa, Buenos Aires, Argentina, v. 2, n. 52, p. 24-40, nov. 2019.

PRESIDENTES e vice-presidentes de comissões de educação das assembleias legislativas. Carta do $1^{\circ}$ Encontro Nacional de Presidentes e Vice-Presidentes de Comissões de Educação das Assembleias Legislativas. Florianópolis, 07 junho 2019.

RIBEIRO, Antonio Carlos Andrade; KLEMANN, Vilmar; RIBEIRO, Mayra Thaís Andrade. O aspecto relacional da accountability social na política de educação brasileira: ações e estratégias da Campanha Nacional pelo Direito à Educação. Cadernos da Escola do Legislativo, Belo Horizonte, v. 19, n. 31, p. 129-162, jun. 2017.

SINDICATO APEOC. Sindicato dos Servidores Públicos Lotados nas Secretarias de Educação e Cultura do Estado do Ceará. Sugestões do Sindicato APEOC. 2019. Disponível em: https://www2.camara.leg.br/atividade-legislativa/comissoes/comissoes-temporarias/ especiais/56a-legislatura/pec-015-15-fundeb/documentos/outros-documentos/sindicatoapeoc. Acesso em: 15 set. 2020.

TPE. Todos Pela Educação. Análise do Substitutivo à Proposta de Emenda à Constituição $n^{0}$ 15/2015. Brasília, 2018. Disponível em: https://www2.camara.leg.br/atividade-legislativa/comissoes/comissoestemporarias/especiais/55a-legislatura/pec-015-15-torna-permanente-o-fundebeducacao/documentos/outros-documentos/emendas-todos-pela-educacao-substitutivo-pec15_15. Acesso em: 15 set. 2020.

TPE. Todos Pela Educação. Todos Pela Educação Apresenta Proposta para Novo Fundeb ao CNE. 2019a. Disponível em: https://www.todospelaeducacao.org.br/conteudo/T odos-Pela-Educacao-apresenta-proposta-para-Novo-Fundeb-ao-CNE. Acesso em: 15 set. 2020.

TPE. Todos Pela Educação. Nota Técnica: análise da relação entre investimento por aluno e qualidade do ensino. Agosto de 2019b. Disponível em: https://www.todospelaeducacao.org .br/_uploads/_posts/319.pdf?477736800. Acesso em: 15 set. 2020. 
TPE. Todos Pela Educação. Novo FUNDEB: mais redistributivo e mais eficiente. Setembro 2019c. Disponível em: https://www.todospelaeducacao.org.br/_uploads/_posts/395.pdf? 1346932076. Acesso em: 15 set. 2020.

TPE. Todos Pela Educação. Análise do Todos pela Educação sobre o Relatório Apresentado na Comissão Especial sobre o Novo FUNDEB. Fevereiro 2020a. Disponível em: https://www.todospelaeducacao.org.br/conteudo/analise-do-todos-pela-educacao-sobreo-relatorio-apresentado-na-comissao-especial-sobre-o-novo-fundeb. Acesso em: 15 set. 2020.

TPE. Todos Pela Educação. Ofício à Comissão Especial da Câmara dos Deputados que Analisa a PEC No 015/2015, Que Torna Permanente o FUNDEB. Junho de 2020b. Disponível em: https://www.todospelaeducacao.org.br/_uploads/_posts/462.pdf?1112 526482/=\&utm_source=Of\%C3\%ADcio\&utm_medium=Fundeb. Acesso em: 15 set. 2020.

UNE. União Nacional dos Estudantes; UBES. União Brasileira dos Estudantes Secundaristas. Posicionamento Público: Excelentíssimo (a) Deputado (a) ajude a salvar nossas escolas!. Agosto de 2019. Disponível em: https://www2.camara.leg.br/atividadelegislativa/comissoes/comissoes-temporarias/especiais/56a-legislatura/pec-015-15fundeb/documentos/sugestoes/SugestesUNEeUBES.pdf. Acesso em: 15 set. 2020.

UNE. União Nacional dos Estudantes; UBES. União Brasileira dos Estudantes Secundaristas. Nota: Sobre a proposta do governo para o novo Fundeb. Julho de 2020. Disponível em: https://ubes.org.br/2020/nota-sobre-a-proposta-do-governo-para-o-novo-fundeb/. Acesso em: 15 set. 2020.

UNDIME. União Nacional Dos Dirigentes Municipais Da Educação. O novo Fundeb como mecanismo de financiamento para a garantia da qualidade da educação. Setembro de 2019. Disponível em: http://undime-sc.org.br/wp-content/uploads/2019/10/Carta-O-novoFundeb-como-mecanismo-de-financiamento-para-a-garantia-da-qualidade-daeduca\%C3\%A7\%C3\%A3o.pdf. Acesso em: 15 set. 2020.

XIMENES, Salomão Barros. Análise e Proposições de Aprimoramento da Minuta de Projeto Substitutivo à PEC 15-A/2015. [minuta para discussão]. 2018. Disponível em: https://media.campanha.org.br/acervo/documentos/NovoFundeb_CamaradosDeputados_20 18_04_24_PropostasEmendas_PEC15-2015-Campanha.pdf. Acesso em: 15 set. 2020.

Micaela Passerino Gluz é pedagoga, professora dos anos iniciais na rede pública de Pelotas/RS e estudante da Especialização em Políticas Públicas e Gestão da Educação da Faculdade de Educação (FACED) da Universidade Federal do Rio Grande do Sul (UFRGS). ORCID: http://orcid.org/0000-0002-7365-7391

E-mail:micpgluz@gmail.com 


\section{Editores do volume 11}

Márcia Aparecida Jacomini - Universidade Federal de São Paulo, Brasil

José Marcelino de Rezende Pinto - Universidade de São Paulo, Brasil

\section{Comitê Editorial}

Nalú Farenzena - Universidade Federal do Rio Grande do Sul, Brasil

Juca Gil - Universidade Federal do Rio Grande do Sul, Brasil

Theresa Adrião - Universidade Estadual de Campinas, Brasil

Ângelo Ricardo de Souza - Universidade Federal do Paraná, Brasil

\section{Conselho Editorial}

\section{Alejandro Morduchowicz}

Universidad Pedagógica, Provincia de Buenos Aires, Argentina

Andréa Barbosa Gouveia

Universidade Federal do Paraná, Brasil

Fernanda Saforcada

Universidade de Buenos Aires, Argentina

Jacques Velloso

Universidade de Brasília, Brasil

João Monlevade

Senado Federal, Brasil

Jorge Abrahão de Castro

Instituto de Pesquisa Econômica Aplicada / IPEA, Brasil

Lisete Regina Gomes Arelaro

Universidade de São Paulo, Brasil

Luis Carlos Sales

Universidade Federal do Piauí, Brasil

Luiz de Sousa Junior

Universidade Federal da Paraíba, Brasil

Luiz Fernandes Dourado

Universidade Federal de Goiás, Brasil

Magna França

Universidade Federal do Rio Grande do Norte, Brasil

Marcos Edgar Bassi

Universidade Federal de Santa Catarina, Brasil

Maria Angélica Pedra Minhoto

Universidade Federal de São Paulo, Brasil

Maria Beatriz Luce

Universidade Federal do Rio Grande do Sul, Brasil

Maria Dilnéia Espíndola Fernandes

Universidade Federal de Mato Grosso do Sul, Brasil

Nelson Cardoso do Amaral

Universidade Federal de Goiás, Brasil

Nicholas Davies

Universidade Federal Fluminense, Brasil

Robert E. Verhine

Universidade Federal da Bahia, Brasil

Romualdo Portela de Oliveira

Universidade de São Paulo, Brasil

Rosana Gemaque Rolim

Universidade Federal do Pará, Brasil

Rubens Barbosa de Camargo

Universidade de São Paulo, Brasil

Theresa Adrião

Universidade Estadual de Campinas, Brasil

Tristan McCowan

University of London, Reino Unido

Vera Jacob

Universidade Federal do Pará, Brasil

Vera Peroni

Universidade Federal do Rio Grande do Sul, Brasil

Vitor Henrique Paro

Universidade de São Paulo, Brasil

\section{Equipe editorial}

Apoio ao Comitê Editorial: Caio Cabral da Silva

Diagramação, Revisão de português e normalização: Edson Leonel de Oliveira

Revisão de inglês: Sabrina Ferreira

Fineduca - Revista de Financiamento da Educação

Associação Nacional de Pesquisa em

Financiamento da Educação

e-mail: revista.fineduca@gmail.com | site: http://seer.ufrgs.br/fineduca 